\title{
Standard Sugar Loading Test
}

\author{
Special Reference to the Possibility of Differentiation of Two \\ Types of Diabetes Mellitus and of Differentiation of Non- \\ diabetics from Diabetics by Sugar Loading Test
}

By

\author{
Yoshio Goto, Kogo Seino and Isao Ito \\ (後藤 由夫) (清野耕吾) (伊藤 伊三雄) \\ From the Medical Clinic of Prof. Kurokawa, \\ Tohoku University, Sendai
}

(Received for publication October 18, 1956)

Many investigators have endeavoured to simplify the technique and interpretation of the sugar loading test. However, the literatures do not show agreement in the interpretation of an equivocal or transitional sugar loading curve. Misinterpretation of an equivocal sugar loading cuve may cause the patient to be denied life insurance or may cause him to undergo unnecessary diabetic treatment.

In the present study the standard sugar loading test was performed in healthy adults, in non-diabetic patients and in diabetic patients. Upon the basis of these results the differentiation of the transitional sugar loading curve from the diabetic curve is discussed. Furthermore, the possibility of determining the need for insulin in a given diabetic patient by means of the sugar loading test is described.

\section{EXPERIMENTAL}

\section{Material and Techniques}

Test subjects consisted of 17 healthy adults, 37 non-diabetic patients, 6 renal glycosuric patients and 76 diabetic patients. They were all hospitalized except the 17 normal adults. In this paper the diabetic patients are classified into two groups according to therapeutic requirements." Type I diabetes mellitus includes patients who are controlled by our high carbohydrate and low fat diet alone, type II diabetes mellitus includes patients who require insulin as well as dietary control.

The sugar loading test was performed as follows. After an overnight fast, $50 \mathrm{~g}$. of glucose dissolved in $250 \mathrm{cc}$. of water was administered orally. Blood specimens were collected from the ear lobe for blood sugar estimation prior to and every 30 minutes after the glucose administration for four hours. Urine specimens were collected every one hour. Blood sugar determinations were made by the Asari modification ${ }^{21}$ of Fujita and Iwatake's micromethod ${ }^{31}$ : and 
urine sugar was estimated by the method of Bertrand.4)

In diabetic patients the sugar loading test was performed within a week of hospitalization, prior to insulin treatment.

\section{Result}

Evaluation of the normal sugar loading curve

Healthy students and interns were chosen as a normal group. The results are summarized in Table $I$ and Fig. 1. The mean fasting blood

TABLE I

Statistical Summary of Results of Oral Sugar Loading Test The values in parentheses represent S.D. (Standard Deviation).

\begin{tabular}{l|ccccccc}
\hline \multirow{4}{*}{ Group } & \multicolumn{8}{|c}{ Blood Sugar (mg. per cent) } \\
\cline { 2 - 8 } & Fasting & $1 \mathrm{hr}$ & $2 \mathrm{hr}$. & $3 \mathrm{hr}$. & $4 \mathrm{hr}$. & Peak Level of Blood Sugar \\
\hline Healthy & 107 & 141 & 98 & 86 & 90 & 159 & 52 \\
& $(10)$ & $(23)$ & $(16)$ & $(10)$ & $(11)$ & $(20)$ & $(19)$ \\
Non-diabetic & 110 & 153 & 106 & 94 & 90 & 165 & 55 \\
& $(12)$ & $(37)$ & $(24)$ & $(18)$ & $(29)$ & $(19)$ & $(18)$ \\
Renal glycosuria & 107 & 148 & 95 & 94 & 94 & 170 & 59 \\
& $(8)$ & $(33)$ & $(12)$ & $(12)$ & $(3)$ & $(19)$ & $(22)$ \\
Type I diabetic & 159 & 272 & 222 & 158 & 127 & 280 & 119 \\
& $(36)$ & $(44)$ & $(58)$ & $(55)$ & $(37)$ & $(52)$ & $(34)$ \\
Type II diabetic & 268 & 405 & 366 & 305 & 266 & 415 & 147 \\
& $(50)$ & $(66)$ & $(68)$ & $(69)$ & $(63)$ & $(67)$ & $(29)$
\end{tabular}

sugar was $107 \mathrm{mg} . \%$ with a S. D. (standard deviation) of $10 \mathrm{mg} . \%$. The upper limit of normal for the fasting blood sugar in the healthy group was $117 \mathrm{mg} . \%$ when $\mathrm{M}+$ S.D. was used. 5 of the 17 cases exceeded this level, but none of them showed a fasting blood sugar value above $120 \mathrm{mg} . \%$ which is widely accepted as the upper limit of normal fasting blood sugar level.5) The blood sugar curve of the healthy group rose rapidly and reached a peak level at $\frac{1}{2}$ or 1 hour and fell rapidly to hypoglycemic level. The mean value of the peak level was $159 \mathrm{mg} . \%$; and the upper limit was $179 \mathrm{mg} . \%$ when $\mathrm{M}+\mathrm{S} . \mathrm{D}$. was used. 3 cases exceeded this level; but all cases were included within $199 \mathrm{mg} . \%(\mathrm{M}+2$ S.D.). These results support the criterion that the normal alimentary hyperglycemia does not exceed $200 \mathrm{mg} . \%$ for capillary blood.5) The maximum increment of blood sugar due to glucose ingestion was $52 \mathrm{mg} . \%$ (ranging 10 to $88 \mathrm{mg} . \%$ ). Hypoglycemic phase began to occur usually at $1 \frac{1}{2}$ or 2 hours; and the blood sugar returned to near the initial value at 3 or 4 hours. The secondary hyperglycemic rebound phenomenon was not observed. The mean 2 hour blood sugar level was $98 \mathrm{mg} . \%(73-134 \mathrm{mg} . \%)$. The upper 

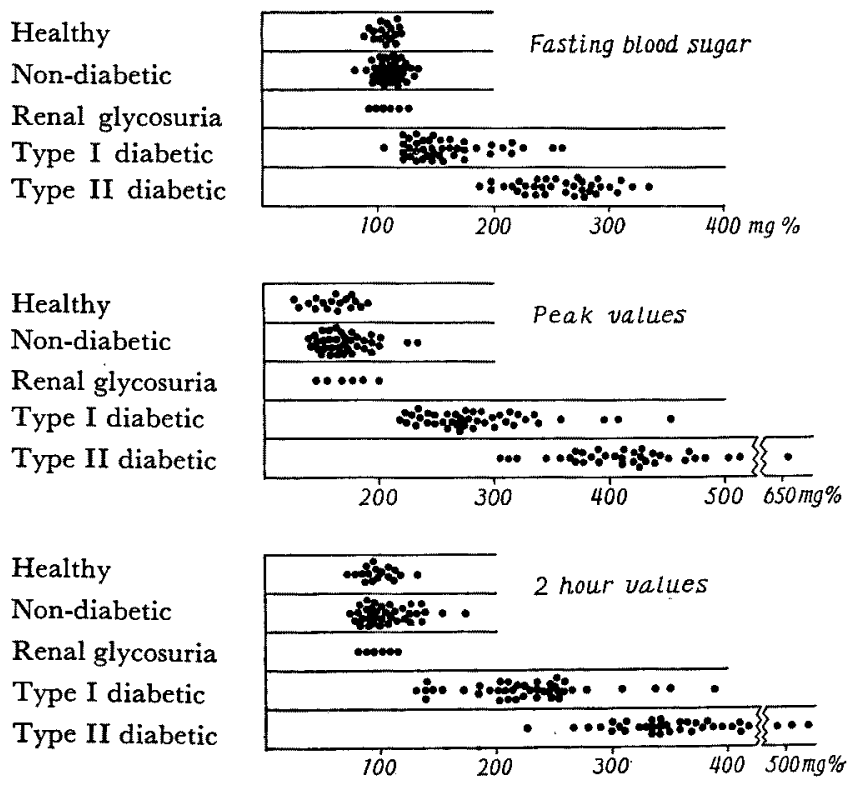

Fig. 1. Distribution of fasting blood sugar levels, peak levels and 2 hour levels in standard sugar loading test.

limit of 2 hour level was $120 \mathrm{mg} . \%$, if $\mathrm{M}+2 \mathrm{~S} . \mathrm{D}$. was used. One of the 17 healthy adults showed a 2 hour blood sugar level of $134 \mathrm{mg} . \%$, a peak level of $191 \mathrm{mg} . \%$ and a 4 hour level of $88 \mathrm{mg} . \%$.

Our criteria for a normal sugar loading curve are: a fasting blood sugar below $120 \mathrm{mg} . \%$, a peak level below $200 \mathrm{mg} . \%$, a 2 hour level below $120 \mathrm{mg} . \%$ and a negative urine sugar. The only case of the 17 normal individuals who could not satisfy these criteria completely had a 2 hour level of $134 \mathrm{mg} . \%$.

Evaluation of the sugar loading curve of non-diabetic patients groups

This group consisted of 37 various hospitalized patients who were thought to have impaired ability to assimilate carbohydrate but negative urine sugar. Their maladies were pancreatic diseases (cancer and inflammation), hepatic diseases (heaptitis, cancer of common bile duct), endocrine diseases (Addison's disease, thyrotoxicosis, myxedema, dwarfism, Simmonds' disease), and other diseases (gastric cancer, narcolepsia, muscular dystrophy, pulmonary tuberculosis). The mean fasting blood sugar was $100 \mathrm{mg} . \%(90-135 \mathrm{mg} . \%)$; and in contrast to the normal group, 7 of the 36 cases have a fasting level above $120 \mathrm{mg} . \%$ but included in 134 mg. $\%(M+2$ S.D. $)$ except one case, whose fasting value exceeded this level by $1 \mathrm{mg} . \%$. The mean peak level was $165 \mathrm{mg} . \%$ (139-232 mg.\%); 
and 35 of the 37 cases didn't exceed $200 \mathrm{mg} . \%$. A case of diabetes insipidus and a gastro-jejunostomized patient showed peak levels of $227 \mathrm{mg} . \%$ and $232 \mathrm{mg} . \%$ respectively, without glycosuria (Fig. 2). In 18 of the 37 cases the peak occurred at $\frac{1}{2}$ hour and in the other 19 cases at 1 hour. The mean maximum increment of blood sugar after glucose ingestion, was $55 \mathrm{mg} . \%$ (21-101 mg.\%). The 2 hour value was $106 \mathrm{mg} . \%$ (76-170 mg. $\%$ ), 9 of the 37 cases above $120 \mathrm{mg} . \%$, and one of them $170 \mathrm{mg} . \%$ with a peak level of $174 \mathrm{mg} . \%$. The mean 4 hour value was $90 \mathrm{mg} . \%$ (63-144 mg.\%).

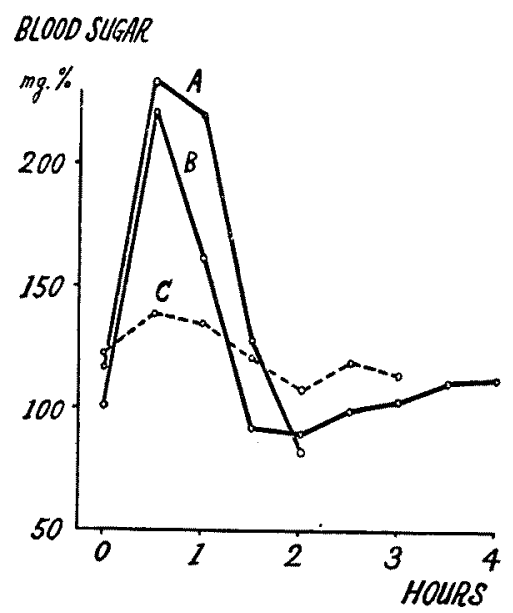

Fig. 2. Glucose loading curves. A ...48 year-old male, gastro-jejunostomized. B . . 28 year-old male, diabetes insipidus. Both peak levels exceed $200 \mathrm{mg} . \%$, but urine sugar excretions were negative. C...broken line represents the sugar loading curve of 20 year-old female, nephrosis. In this case four urine specimens including fasting one, gave positive sugar reaction.

Evaluation of the sugar loading curve in type I diabetes group

This group consisted of patients whose diabetic symptoms could be controlled by our high carbohydrate low fat diet alone (250-350 g. carbohydrate, $30-40 \mathrm{~g}$. fat, $70-100 \mathrm{~g}$. protein, 30-35 Cal $/ \mathrm{kg}$ ). The mean value of fasting blood sugar was $159 \mathrm{mg} . \%(104-256 \mathrm{mg} . \%)$ and that of $78 \%$ of type I diabetics ranged from 120 to $200 \mathrm{mg} . \%$. 6 of 41 showed fasting levels above $200 \mathrm{mg} \%$; and one case showed a fasting level below 120 mg. \%. The blood sugar rose rapidly to its highest level in 1 or $1 \frac{1}{2}$ hour and fell gradually to hypoglycemic levels. The hypoglycemia rose to the initial value very slowly. The mean peak value was $280 \mathrm{mg} . \%(218-$ $452 \mathrm{mg} . \%$ ). The maximum increment of blood sugar was $119 \mathrm{mg} . \%$ 
(84-181 mg.\%). The mean 2 hour value was $222 \mathrm{mg} . \%$ (142-378 mg.\%), and there is no case whose 2 hour value was below $120 \mathrm{mg} . \%$. The mean 4 hour value was $127 \mathrm{mg} . \%(69-227 \mathrm{mg} . \%)$. 10 cases showed a 4 hour value below $100 \mathrm{mg} . \%$ and 3 cases above $200 \mathrm{mg} . \%$. In all cases urine sugar was positive.

\section{Evaluation of the sugar loading curve in type II diabetes group}

This group consisted of patients whose diabetic symptoms were controlled by insulin in addition of our high carbohydrate low fat diet. The mean fasting blood sugar of the type II diabetic group was $268 \mathrm{mg} . \%$ $(187-472 \mathrm{mg} . \%)$; and $91 \%$ of this group showed their fasting value above $200 \mathrm{mg} . \%$. The blood sugar rose rapidly to its peak at 1 or $1 \frac{1}{2}$ hour and decreased gradually. The hypoglycemia began to occur usually at $3 \frac{1}{2}$ hours. In 14 of the 35 cases hyperglycemia was protracted; and the blood sugar did not return to the fasting level within 4 hours. The mean value of a peak level was $415 \mathrm{mg} . \%(308-658 \mathrm{mg} . \%)$. In 21 of the 35 cases $(60 \%)$ the peak value was above $400 \mathrm{mg} . \%$. The maximum increment of blood sugar was $144 \mathrm{mg} . \%(94-220 \mathrm{mg} . \%)$. The mean 2 hour value was $366 \mathrm{mg} . \%(226-520 \mathrm{mg} . \%)$. In 30 of the 35 the 2 hour value was above $300 \mathrm{mg} . \%$. The mean 4 hour value was $266 \mathrm{mg} . \%$ (160-406 mg. $\%$ ); and in 31 of the 35 cases this was above $200 \mathrm{mg} . \%$. In all cases, urine sugar was positive.

\section{Evaluation of the sugar loading curve in renal glycosuria}

Joslin applied this name to the condition in which the renal threshold is extremely low, as indicated by the fact that all specimens of urine examined, including those after an overnight fast, contain sugar. $\left.{ }^{6}\right)$ Such cases are very rare. On the contrary, Hatlehol defined renal glycosuria as the presence of a positive urine sugar reaction without diabetic symptoms and the subsequent absence of true diabetes during prolonged observation. ${ }^{7}$ ) In his paper there are some cases of renal glycosuria which have a hyperglycemic peak above $200 \mathrm{mg} . \%$, in some cases $300 \mathrm{mg} . \%$. We do not accept this definition. We define renal glycosuria as that condition in which the alimentary hyperglycemic peak and a 2 hour value are within normal limits but the urine sugar is positive.

The mean fasting blood sugar of our 6 cases of renal glycosuria was $107 \mathrm{mg} . \%(94-121 \mathrm{mg} . \%$ ) and the mean peak level was $170 \mathrm{mg} . \%$ (139$198 \mathrm{mg} . \%$ ). The 2 hour values ranged between 80 and $110 \mathrm{mg} . \%$. In all cases urine sugar became positive after sugar ingestion, but the fasting urine specimens gave negative sugar reactions except in one case, whose fasting blood sugar was $121 \mathrm{mg} . \%$ and peak level was $139 \mathrm{mg} . \%$ (Fig. 2).

The differentiation of mild diabetes mellitus and renal glycosuria is 
relatively easy if our definition of renal glycosuria is used. But this differentiation may be difficult, if an extremely low renal threshold for sugar (for example below $100 \mathrm{mg} . \%$ ) is necessary for the diagnosis of renal glycosuira. If the latter definition is accepted, how shall we diagnose the case in which the sugar loading curve is normal and glycosuria appears only when the blood sugar is above $150 \mathrm{mg} . \%$ ? Is this a mild case of diabetes or is this a so-called potential, latent or pre-diabetes? If such a case represents latent diabetes, the question arises whether lowered renal threshold or prolonged alimentary hyperglycemia is the essential disturbance in diabetes mellitus. It is hard to believe that the lowered renal threshold is a prodromal finding of diabetes mellitus. We feel that the slight increase in hyperglycemic peak exceeding the normal limit and/or the protraction of alimentary hyperglycemia may be an essential finding even in the latent stage of diabetes mellitus. Therefore, it is more proper to regard the patient who has glycosuria and a normal sugar loading curve as a renal glycosuric patient in whom there is normal sugar assimilation but an impaired reabsorption of sugar in the kidney. According to our opinion, the glycosuric patient, whose loading curve has a peak value below $200 \mathrm{mg} . \%$ and a 2 hour value below $120 \mathrm{mg} . \%$, is a renal glycosuric patient in a broad sense; and the glycosuric patient, whose peak value in sugar loading curve is above $200 \mathrm{mg} . \%$ for capillary blood, is a mild case of diabetes mellitus, even if his glycosuria will disappear by a slight diet restriction. "Latent diabetes" or "potential diabetes" seems to be an unnecessary nomenclature. If these words are retained, we prefer to use the term "latent diabetes" for the patient, whose sugar loading curve has a peak value above $200 \mathrm{mg} \%$ and a 2 hour value above 120 mg. $\%$ with negative urine sugars.

There are several theoretical explanations of renal glycosuria: the theory of decreased phosphorylation in tubuli contorti due to hypofunction of adrenal cortex; the pituitary hormone theory; the lability of the vegetative nervous system theory. Renal glycosuria was provoked clinically during ACTH treatment. ${ }^{81}$ Yet the etiology is not clear.

On of our 6 cases, a 20 year-old woman, suffered from severe nephrosis. Her urine protein concentration was $30 \%$ and serum protein was $3.8 \%$. Urine sugar was positive throughout her clinical course. Her sugar loading curve was normal although the fasting blood sugar was $121 \mathrm{mg} . \%$, as shown in Fig. 2. It seems proper to call such a case secondary renal glycosuria, in contrast to idiopathic renal glycosuria in which other symptoms are not manifest.

Is it always possibile to differentiate diabetic and non-diabetic by the sugar loading test? 
It is easy to distinguish the typical normal sugar loading curve from the diabetic curve, but we are sometimes confused in the diagnostic evaluation of an abnormal sugar loading curve, which does not satisfy the criteria of a normal sugar loading curve nor that of a diabetic curve. Some of these abnormal curves may originate in careless test conditions; such as previous starvation, carbohydrate restriction, diarrhea, insomnia, etc.

The transitional cases are those with an abnormal fasting blood sugar, a normal peak, and a normal 2 hour value; those with an abnormal peak level, a normal fasting, and a normal 2 hour value; and those with an abnormal fasting, an abnormal 2 hour value, but a normal peak level, etc. How shall we interprete such cases?

A high fasting blood sugar is observed in a healthy test subject, when he is tired or drowsy. A 29 year-old physician was examined on the morning after night duty and his fasting blood sugar found to be $147 \mathrm{mg} . \%$ for capillary blood and $146 \mathrm{mg} . \%$ for venous blood without glycosuria. Few weeks later when blood sugar examinations were made again two offduty mornings his fasting blood sugar values were $106 \mathrm{mg} . \%$ and $94 \mathrm{mg} . \%$. The fasting blood sugar level of a 22 year-old laboratory technician was determined every 10 minutes from 4:50 a.m. to 8:00 a.m. after night duty. The results are shown in Fig. 3. The blood sugars fluctuate from

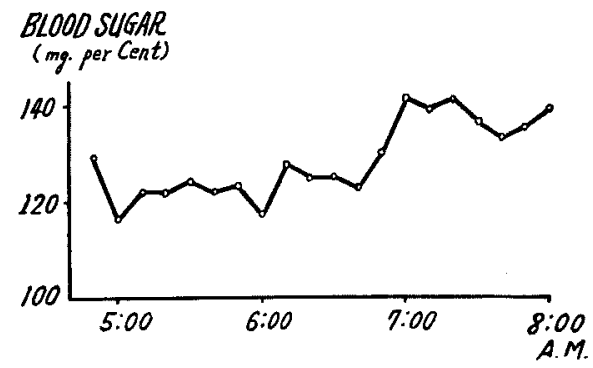

Fig. 3. Oscillation in the fasting blood sugar. 20 year-old male. $5: 20$ a.m. to $6: 40$ a.m., sleeping during part of this time.

116 to $144 \mathrm{mg} . \%$ within 3 hours. Later a sugar loading test confirmed his normal carbohydrate assimilating power. It was observed by Hatlehol ${ }^{9}$ and Kuzuya ${ }^{10)}$ that the fasting blood sugar rises in the early morning. Therefore, if the blood sugar estimation is made before 8 a.m. a moderately high fasting blood sugar level does not always mean a diabetic condition. But if repeated estimations of fasting blood sugar show constant high values, we should regard such a case as diabetic.

When the hyperglycemic peak of the sugar loading curve exceeds $200 \mathrm{mg} . \%$, should we regard the loading curve as diabetic? The normal hyperglycemic peak usually does not exceed $200 \mathrm{mg} . \%$, but it is frequently 
observed that some people show a hyperglycemic peak above $200 \mathrm{mg} . \%$ without glycosuria. It has been observed that old people have such curves, but they have no diabetic symptoms and do not develop true diabetes. It has been shown that the rapid absorption of sugar from the intestine causes a steep high-peaked hyperglycemic curve. Such a curve has been called a lag storage curve or oxyhyperglycemia. ${ }^{5)}$ We obtained such a curve in a case of diabetes insipidus and in a gastro-jejunostomized patient (Fig. 3). Their urine specimens gave a negative sugar reaction. Therefore, a hyperglycemic peak of over $200 \mathrm{mg} . \%$ does not always mean diabetes mellitus. However, non-diabetics cannot have a hyperglycemic peak above $230 \mathrm{mg} . \%$ in his loading curve, or at least above $250 \mathrm{mg} . \%$.

Protraction of alimentary hyperglycemia is one of the characteristic findings in diabetes mellitus. In 12 of the 17 normal cases, and in 25 of the 36 non-diabetic patients, the hyperglycemia fell to fasting blood sugar levels within 2 hours; on the contrary, this occurred in only one case of the 41 type I diabetics and in none of the 35 type II diabetics. All of the diabetic cases in our series showed a 2 hour value above $140 \mathrm{mg} . \%$, and 8 of the 36 non-diabetic patients showed a 2 hour value above $120 \mathrm{mg} . \%$. These 8 cases consisted of 3 cases of strumitis, 2 cases of pancreatic cancer, one case each of lung cancer, cholelithiasis, and myelocytic leukemia. Only one case of the 17 normal adults showed a 2 hour value above 120 mg. \%. Hence, if the 2 hour value does not exceed $120 \mathrm{mg} . \%$, the diagnosis of diabetes mellitus is denied, but a 2 hour value above $120 \mathrm{mg} . \%$ does not always mean diabetes mellitus.

Speaking conclusively, an equivocal sugar loading curve is infrequently obtained in clinical practice, and the diagnosis of such a curve is difficult. Further clinical observation, past history, and repeated sugar loading test, are necessary to designate the case diabetic or non-diabetic.

Can we decide by means of the sugar loading test whether the diabetic patient will need insulin?

If we can differentiate type I diabetes and type II diabetes by means of sugar loading test at the beginning of hospitalization or in the ambulatory clinic, the need for insulin treatment in a given patient may be estimated in advance. For this purpose the present attempt was made to compare the blood sugar curves of these two diabetic groups.

If the criterion is made that the fasting value of type I diabetics is below $195 \mathrm{mg} . \%(M+S . D$.$) and that of type II diabetics above 218 \mathrm{mg} . \%$ (M-S.D.) $18.4 \%$ of our diabetic patients are misjudged, that is, 8 cases of the 41 type I diabetics and 5 of the 35 type II diabetics deviate from these two limit values. If the upper limit of 2 hour value for type I diabetics is $280 \mathrm{mg} . \%$ (M+S.D.), 5 of the 41 cases exceed this value; and 


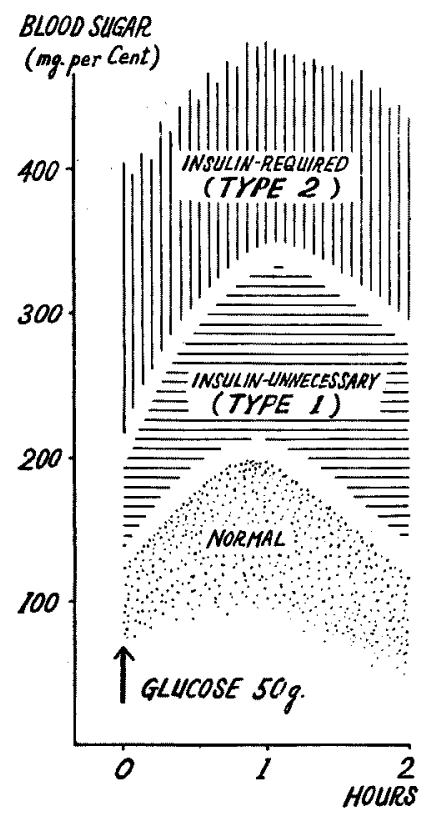

Fig. 4. Gross distribution of blood sugar values in sugar loading test among insulin-required type diabetes (type II), insulin-unnecessary type diabetes (type I), and normal group.

if the lower limit of that for type II diabetics is $298 \mathrm{mg} . \%$ (M-S.D.), 5 of the 35 cases are below this value. The upper limit of peak value for type I diabetics is $332 \mathrm{mg} \% \%$ when M+S.D. is used and 6 of 41 cases exceed this level. The lower limit of peak value for type II diabetics is $348 \mathrm{mg} . \%$ when $\mathrm{M}-\mathrm{S}$.D. is used and 4 of 35 are below this value. If the criterion is made that the maximum urine sugar concentration of type I diabetics is less than $3.7 \%(M+$ S.D. $)$ and the maximum sugar concentration of urine specimens for type II diabetics is more than $3.8 \%$ (M-S. D.), 8 of the 41 type I diabetics and 2 of the 35 type II diabetics deviate from these limit values.

If the criteria are made that in type I diabetics the fasting level is below $195 \mathrm{mg} . \%$, the peak level below $332 \mathrm{mg} . \%$, the 2 hour level below $280 \mathrm{mg} . \%$ and the maximum urine sugar concentration below $3.7 \%$; and that in type II diabetics the fasting level is above $218 \mathrm{mg} . \%$, the peak level above $348 \mathrm{mg} . \%$, the 2 hour level above $298 \mathrm{mg} . \%$, and the maximum urine sugar concentration above $3.8 \%$, as shown in Fig. $4,80 \%$ of our 76 diabetic patients are correctly classfied as type I or type II. Only one case of 41 type I diabetic patients satisfied the above criteria of type 
II diabetes and 2 cases of the 35 type II diabetic patients satisfied those of type I diabetes. Thus by means of the sugar loading test we may determine whether the untreated diabetic patient will subsequently require insulin as well as dietary control for the management of his diabetes.

\section{SUMMARY}

The standard sugar loading test ( $50 \mathrm{~g}$. of glucose) was performed in normal adults, non-diabetic patients, and diabetic patients. Our critieria for normal sugar loading test are: a fasting blood sugar below $120 \mathrm{mg} . \%$, a peak level below $200 \mathrm{mg} . \%$, a 2 hour level below $120 \mathrm{mg} . \%$ for capillary blood, and a negative urine sugar. In diabetic patients, evaluation of the loading curve may indicate whether insulin is needed in the treatment schedule. If the fasting blood sugar is below $195 \mathrm{mg} . \%$, the 2 hour value below $280 \mathrm{mg} . \%$, and the peak level below $332 \mathrm{mg} . \%$, his diabetic symptoms can be controlled without insulin injections; on the contrary, if the fasting blood sugar is above $218 \mathrm{mg} . \%$, the 2 hour value above $298 \mathrm{mg} . \%$, and the peak level above $348 \mathrm{mg} . \%$, insulin must be used in addition to dietary treatment. The interpretation of transitional and equivocal sugar loading curves and the definition of renal glycosuria were also discussed.

\section{References}

1) Kurokawa, Folia endocrinol. japonica, 1951, 27, 141.

2) Asari, Tokyo Ijishinshi (Jap.), 1939, 2599.

3) Fujita \& Iwatake, Biochem. Zschr., 1931, 242, 43.

4) Bertrand, Bull. soc. chim., 1906, 35, 1285.

5) Lawrence, Med. Clin. North Amer., 1947; 289.

6) Joslin, The Treatment of Diabetes Mellitus, Philadelphia, Lea \& Febiger, 1948.

7) Hatlehol, Acta med. Scand., 1936, Suppl. 78, 646.

8) Kass, Ingbar \& Finland, Proc. Soc. Exp. Biol. Med., 1950, 73, 669.

9) Hatlehol, Acta med. Scand., 1924, Suppl. 8.

10) Kuzuya, Nihon Shokakibyo Gakkai Zasshi (Transactions of the Gastroenterolog. Soc. of Japan), 1953, 50, No. 7, 12. 